\title{
A 16-yr Follow-up of the European Randomized study of Screening for Prostate Cancer
}

\author{
Jonas Hugosson ${ }^{a, *}$, Monique J. Roobol ${ }^{b}$, Marianne Månsson $^{a}$, Teuvo L.J. Tammela ${ }^{c}$, \\ Marco Zappa $^{d}$, Vera Nelen ${ }^{e}$, Maciej Kwiatkowski ${ }^{f, g}$, Marcos Lujan $^{h}$, Sigrid V. Carlsson ${ }^{a, i}$, \\ Kirsi M. Talala ${ }^{j}$, Hans Lilja $^{k, l, m, n, o}$, Louis J. Denis ${ }^{p}$, Franz Recker $^{f}$, Alvaro Paez $^{q}$, Donella Puliti ${ }^{d}$, \\ Arnauld Villers $^{r}$, Xavier Rebillard ${ }^{s}$, Tuomas P. Kilpeläinen ${ }^{t}$, Ulf H. Stenman ${ }^{u}$, \\ Rebecka Arnsrud Godtman ${ }^{a}$, Karin Stinesen Kollberg ${ }^{a}$, Sue M. Moss ${ }^{v}$, Paula Kujala ${ }^{u}$, \\ Kimmo Taari $^{t}$, Andreas Huber ${ }^{w}$, Theodorus van der Kwast ${ }^{x}$, Eveline A. Heijnsdijk ${ }^{y}$, \\ Chris Bangma ${ }^{b}$, Harry J. De Koning ${ }^{y}$, Fritz H. Schröder ${ }^{b}$, Anssi Auvinen ${ }^{z}$, \\ on behalf of the ERSPC investigators
}

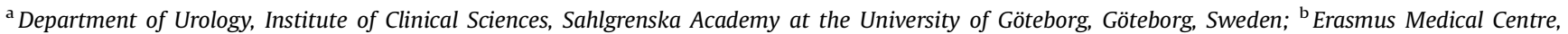
Rotterdam, The Netherlands; ${ }^{\mathrm{c}}$ University of Tampere, Faculty of Medicine and Life Sciences, Tampere, Finland; ${ }^{\mathrm{d}}$ ISPRO, Oncological network, Prevention, and Research Institute, Florence, Italy; ${ }^{\mathrm{e}}$ Provinciaal Instituut voor Hygiëne, Antwerp, Belgium; ${ }^{\mathrm{f}}$ Department of Urology, Cantonal Hospital Aarau, Aarau, Switzerland; ${ }^{\mathrm{g}}$ Department of Urology, Academic Hospital Braunschweig, Braunschweig, Germany; ${ }^{\mathrm{h}}$ Urology Department, Hospital Infanta Cristina, Parla, Madrid, Spain; ${ }^{\mathrm{i}}$ Departments of Surgery (Urology Service) and Epidemiology and Biostatistics, Memorial Sloan Kettering Cancer Center, New York, NY, USA; ${ }^{\mathrm{j}}$ Finnish Cancer Registry, Helsinki, Finland; ${ }^{\mathrm{k}}$ Department of Laboratory Medicine, Memorial Sloan Kettering Cancer Center, New York, NY, USA; ${ }^{1}$ Department of Surgery, Memorial Sloan Kettering Cancer Center, New York, NY, USA; ${ }^{\mathrm{m}}$ Department of Medicine, Memorial Sloan Kettering Cancer Center, New York, NY, USA; ${ }^{\mathrm{n}}$ Nuffield Department of Surgical Sciences, University of Oxford, Oxford, UK; ${ }^{\circ}$ Department of Translational Medicine, Lund University, Skåne University Hospital, Malmö, Sweden; ${ }^{\mathrm{p}}$ Europa Uomo, Oncology Centre Antwerp, Antwerp, Belgium; ${ }^{\mathrm{a}}$ Department of Urology, Hospital Universitario de Fuenlabrada, Madrid, Spain; ${ }^{\mathrm{r}}$ Department of Urology, CHU Lille, University Lille Nord de France, Lille, France; ${ }^{\mathrm{s}}$ Urology Department, Clinique Beau Soleil, Montpellier, France; ${ }^{\mathrm{t}}$ Department of Urology, University of Helsinki and Helsinki University Hospital, Helsinki, Finland; ${ }^{\mathrm{u}}$ Department of Pathology, Fimlab Laboratories, Tampere, Finland; ${ }^{\mathrm{v}}$ Centre for Cancer Prevention, Wolfson Institute of Preventative Medicine, Queen Mary University of London, Charterhouse Square, UK; ${ }^{\mathrm{w}}$ Department of Laboratory Medicine, Cantonal Hospital Aarau, Aarau, Switzerland; ${ }^{\mathrm{x}}$ Laboratory Medicine Program, University Health Network, Toronto, Canada; ${ }^{\mathrm{y}}$ Erasmus Medical Centre, Department of Public Health, Rotterdam, The Netherlands; ${ }^{2}$ Prostate Cancer Research Center, Faculty of Social Sciences, University of Tampere, Tampere, Finland
\end{abstract}

\section{Article info}

Article history:

Accepted February 7, 2019

Associate Editor:

Giacomo Novara

\begin{abstract}
Background: The European Randomized study of Screening for Prostate Cancer (ERSPC) has previously demonstrated that prostate-specific antigen (PSA) screening decreases prostate cancer (PCa) mortality.

Objective: To determine whether PSA screening decreases PCa mortality for up to $16 \mathrm{yr}$ and to assess results following adjustment for nonparticipation and the number of screening rounds attended.

Design, setting, and participants: This multicentre population-based randomised screening trial was conducted in eight European countries. Report includes

* Corresponding author. Institute of Clinical Sciences, Sahlgrenska Academy at the University of Göteborg, Bruna Stråket 11 B, SE-413 45 Göteborg, Sweden. Tel. +46 3134290 17;

Fax: +46 31812533 .

E-mail address: jonas.hugosson@gu.se (J. Hugosson).
\end{abstract}

https://doi.org/10.1016/j.eururo.2019.02.009

0302-2838/৫ 2019 Published by Elsevier B.V. on behalf of European Association of Urology. 


\section{Keywords:}

Prostate cancer

Screening

Prostate-specific antigen

Mortality
182160 men, followed up until 2014 (maximum of $16 \mathrm{yr}$ ), with a predefined core age group of 162389 men (55-69 yr), selected from population registry.

Outcome measurements and statistical analysis: The outcome was PCa mortality, also assessed with adjustment for nonparticipation and the number of screening rounds attended.

Results and limitations: The rate ratio of PCa mortality was 0.80 (95\% confidence interval $[\mathrm{CI}] 0.72-0.89, p<0.001$ ) at $16 \mathrm{yr}$. The difference in absolute PCa mortality increased from $0.14 \%$ at $13 \mathrm{yr}$ to $0.18 \%$ at $16 \mathrm{yr}$. The number of men needed to be invited for screening to prevent one PCa death was 570 at $16 \mathrm{yr}$ compared with 742 at $13 \mathrm{yr}$. The number needed to diagnose was reduced to 18 from 26 at $13 \mathrm{yr}$. Men with PCa detected during the first round had a higher prevalence of PSA $>20 \mathrm{ng} / \mathrm{ml}(9.9 \%$ compared with $4.1 \%$ in the second round, $p<0.001$ ) and higher PCa mortality (hazard ratio $=1.86, p<0.001$ ) than those detected subsequently.

Conclusions: Findings corroborate earlier results that PSA screening significantly reduces PCa mortality, showing larger absolute benefit with longer follow-up and a reduction in excess incidence. Repeated screening may be important to reduce PCa mortality on a population level.

Patient summary: In this report, we looked at the outcomes from prostate cancer in a large European population. We found that repeated screening reduces the risk of dying from prostate cancer.

(C) 2019 Published by Elsevier B.V. on behalf of European Association of Urology.

\section{Introduction}

The European Randomized study of Screening for Prostate Cancer (ERSPC) was initiated in 1993, with the primary aim to investigate the effect of regular prostate-specific antigen (PSA) screening on prostate cancer (PCa) mortality. Findings were previously reported on three occasions, as prespecified in the study protocol at 9, 11, and 13 yr of follow-up [13]. The latest report (2014) showed that PSA screening increased PCa incidence 1.6-fold and the relative reduction in PCa mortality was $21 \%$ at $13 \mathrm{yr}$ of follow-up [3]. This is the 16 -yr main endpoint follow-up in order to quantify the long-term harms and benefits of screening. Secondary aims were to investigate how variations in screening attendance and duration of screening (one test only vs repeated testing) affected PCa mortality and whether this could explain the observed variations in outcome between different screening trials as well as between different ERSPC centres [3,4].

\section{Patients and methods}

\subsection{Study design and participants}

The ERSPC, described previously [1-3], is a multicentre randomised screening trial for PCa in eight European countries (Fig. 1). It started in Belgium and the Netherlands (1993), and the last country to join was France in 2003. Minor variations in screening protocols between centres were accepted, but compulsory criteria for participation were defined [5], including PSA as the primary screening test, followed by systematic prostate biopsies for men with elevated PSA; a core age group of men 55$69 \mathrm{yr}$ old at randomisation; repeated screening invitations; and regular data delivery to an independent central database (age groups between 50 and $74 \mathrm{yr}$ were invited in some centres). Stopping age for screening invitations varied between 67 and $78 \mathrm{yr}$. Most centres used a $4-\mathrm{yr}$ interval, but Sweden and France used a 2-yr interval and Belgium a 7-yr interval. A minimum of two and a maximum of eight invitations were used for the core age group, and the duration of screening (time from the first to the last invitation) varied between $4 \mathrm{yr}$ (oldest men in Finland) and $16 \mathrm{yr}$ (the Netherlands and Sweden). The primary screening tool was PSA. To achieve high quality, a uniform PSA method was chosen (Tandem
R; Hybritech). A quality assurance programme was designed to guarantee accuracy of the test across centres. Additional screening tools were employed in some centres. In the Netherlands, digital rectal examination (DRE) was used during 1993-1996 in men with PSA 1.0$4.0 \mathrm{ng} / \mathrm{ml}$. In Finland, DRE was used in 1996-1998, and the ratio of free to total PSA was used since 1999 in men with a PSA level of $3.0-3.9 \mathrm{ng} / \mathrm{ml}$. Since 1996, most centres used a PSA level of $\geq 3.0 \mathrm{ng} / \mathrm{ml}$ as the definition of a positive screening test. Men with a positive screening test were recommended DRE, transrectal ultrasound of the prostate, and systematic prostate biopsies. Initially, sextant biopsies were the standard, but this was later changed to 10-12 cores. A summary of the characteristics by centre is provided in Table 1 . French data were excluded from the combined analysis, as these two centres failed to comply with a primary criterion (screening participation $>50 \%$; Table 1 ) [6]. Ethical approval was obtained separately for each participating country.

\subsection{Randomisation and masking}

Two types of randomisations were used: randomisation before consent (Zelen-type effectiveness design in Sweden, Finland, and Italy) and randomisation after consent (efficacy design in the other countries). Randomisation was done by computer-generated random numbers, with eligible participants identified in population registers. Trial group allocation was masked for determination of the main outcome.

\subsection{Outcomes}

The primary outcome was PCa mortality. For deceased men with PCa, medical records were evaluated by a cause of death (COD) committee using a standardised flow-chart to establish the COD [7]. The COD committee was masked regarding the randomisation arm. Official CODs were used in Finland since 2003 after demonstrating a very high concordance with that obtained by the local COD committee [8]. PCa incidence and vital status were monitored regularly in all randomised men and reported biannually to the central database. For men with PCa, TNM stage, PSA, Gleason score, and primary treatment were abstracted from medical records. A scientific committee established quality criteria and other committees monitored the conduct, progress of the trial, PSA harmonisation, and assignment of Gleason grades [5]. This report includes follow-up through December 31, 2014 or a maximum of $16 \mathrm{yr}$ after randomisation. 


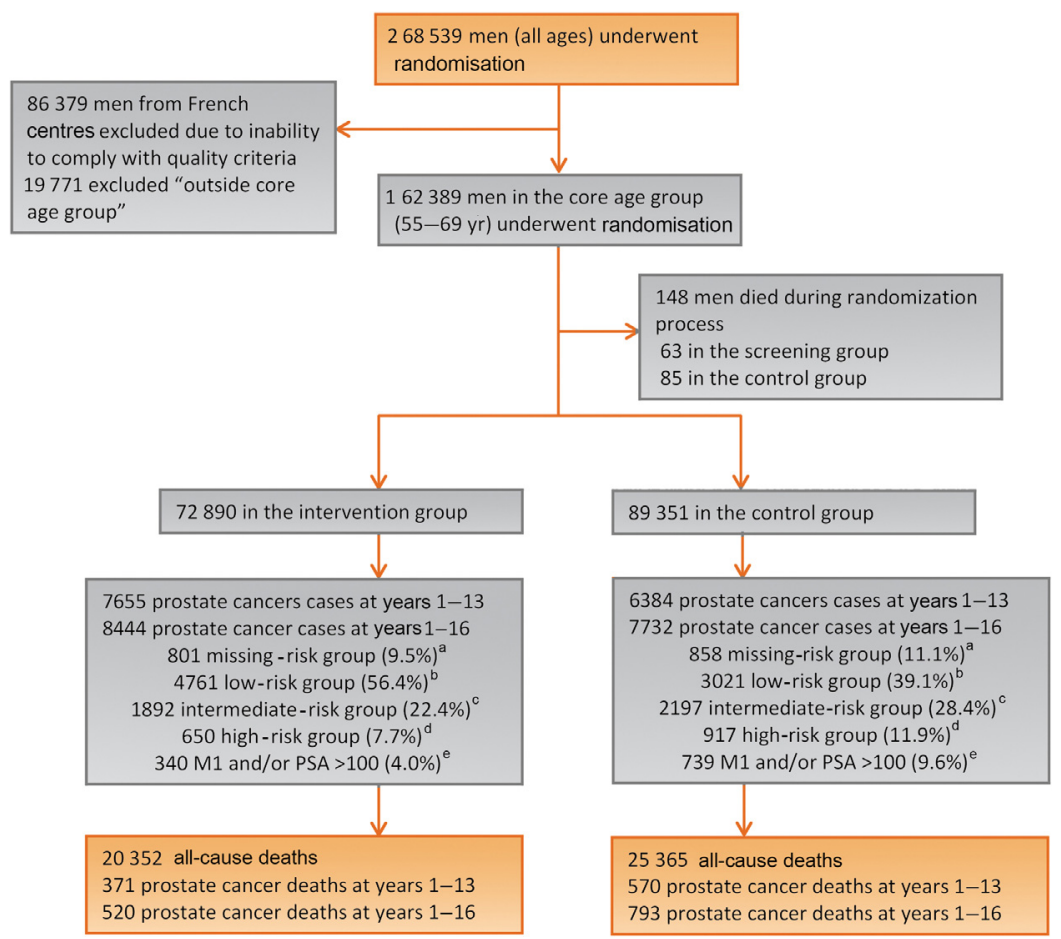

Fig. 1 - Trial profile (core age group). GS = Gleason score; $M 1$ = evidence of metastases on imaging or PSA $>100 \mathrm{ng} / \mathrm{ml}$; PSA = prostate-specific antigen. ${ }^{\text {a }}$ Missing = missing T stage or GS, not M1 or PSA $>100 .{ }^{b}$ Low risk $=\mathrm{T1}$, and T1 with GS $\leq 6$. ${ }^{\mathrm{c}}$ Intermediate risk $=\mathrm{T1}$, and T2 with GS 7 and T3 with GS $\leq 7$. ${ }^{\mathrm{d}}$ High risk $=\mathrm{T1}$, T2, and T3 with GS 8-10 and T4 with any GS. ${ }^{\mathrm{e}} \mathrm{M1}$ or PSA $>100$, any T stage, or GS.

\subsection{Statistical analysis}

\subsubsection{Primary analysis}

The primary analysis evaluated PCa mortality and focused on the core age group of men 55-69-yr old, with follow-up through 2014 truncated at 9, 11, 13 , and $16 \mathrm{yr}$. The main analysis was carried out according to the intentionto-screen principle, that is, comparing groups formed by randomisation (regardless of assignment compliance). Incidence and mortality rates, and risks were calculated by dividing the number of events by the number of person years and the number of men, respectively. Rate ratios (RRs; ratio of incidence per person year), risk ratios (ratio of incidence per man), and the corresponding differences were calculated using Poisson regression analysis, with the control arm for Finland weighted by 1:1.5 due to unequal allocation (agreed upon when Finland joined the trial). Confidence intervals (CIs) for rate and risk differences were calculated by Wald's method, with standard errors derived by the delta method. For the number needed to invite (NNI), the Cls were derived as 1 over the intervals for the differences in the risk of PCa mortality. The $p$ values are two sided. No adjustment of significance for alpha-spending in sequential analyses was applied because the present analysis is protocol based and not driven by statistical significance $[9,10]$. The NNI to avert one PCa death was calculated as the inverse of the absolute risk difference in PCa deaths. The number needed to detect (NND) was defined as the NNI multiplied by the excess incidence of PCa in the screening group. Both the graphs on cumulative PCa incidence and mortality in the control and screening arms, and the graph on survival after screen-detected PCa are based on Nelson-Aalen estimates of survival. Cumulative incidence and mortality curves adjusted for the competing risk of death of other causes follow the approach described in the study of Kalbfleisch and Prentice [11].

\subsubsection{Secondary analysis}

In a secondary analysis, PCa mortality was assessed from diagnosis in those men diagnosed within the programme. Men with screen-detected cancer in round 1 were compared with screen-detected men during subsequent screening rounds. Cox regression analysis was used.

To evaluate the effect of attending at least one screening round, adjusted RRs were calculated with adjustment for nonparticipation [12]. The proportion of complete nonattendees (ie, never participating) in the screening group and the PCa mortality among them were calculated. The control group is then considered to consist of a nonattender part of the same size and the same PCa mortality rate as the nonattender part of the screening group, allowing us to calculate the adjusted mortality rate among those who participated at least once.

Additionally, we estimated an adjusted RR in men who attended at least twice. Here, we defined two groups of attendees: (1) all men who participated only once and (2) men participated at least twice. The proportion of men attending one screening round only and the PCa mortality in this group were calculated. The underlying PCa mortality in this group (screened only once) in the absence of screening is unknown, but a recent study showed no effect of one screening round only [4]. We therefore carried out analyses based on mortality reductions of $0 \%$ (there was no benefit to men with cancer detected at the first screen) up to $25 \%$ (ie, the benefit of the first screening was the same as that at later screening round) in men screened only once. This trial is registered with Current Controlled Trials (number ISRCTN49127736).

Statistical analyses were performed in R Statistical Software (version 3.3.1; Foundation for Statistical Computing, Vienna, Austria).

\section{Results}

\subsection{Primary analyses}

A total of 182160 men were randomised, of whom 162389 were part of the core age group of men 55-69 yr old. Figure 1 shows the trial profile. Men randomised to the 
Table 1 - Characteristics of the study overall and by centre

\begin{tabular}{|c|c|c|c|c|c|c|c|c|c|c|c|}
\hline & Belgium & Finland & Italy & The Netherlands & Spain & Sweden & Switzerland & Total (excl. France) & France, Herault & France, Tarn & Total \\
\hline $\begin{array}{l}\text { Age at } \\
\text { randomisation, } \\
\text { (yr), median (IQR) }\end{array}$ & $63(60.2,66.2)$ & $59(54.8,62.7)$ & $62(58.4,65.9)$ & $62(58.0,65.6)$ & $60(57.4,64.2)$ & $60(57.2,62.4)$ & $61(57.8,65.1)$ & $60(57.1,64.2)$ & $62(58.8,65.9)$ & $62(57.9,66.1)$ & $61(57.9,65.0)$ \\
\hline Randomised $(n)$ & 8562 & 80379 & 14515 & 34833 & 2197 & 11852 & 9903 & 162241 & 57643 & 21350 & 241234 \\
\hline Screening, $n$ (\%) & $4307(50 \%)$ & $31970(40 \%)$ & 7265 (50\%) & $17443(50 \%)$ & $1056(48 \%)$ & $5901(50 \%)$ & $4948(50 \%)$ & 72890 (45\%) & $28784(50 \%)$ & $10879(51 \%)$ & $112553(47 \%)$ \\
\hline Control, $n(\%)$ & $4255(50 \%)$ & 48409 (60\%) & 7250 (50\%) & $17390(50 \%)$ & $1141(52 \%)$ & $5951(50 \%)$ & $4955(50 \%)$ & 89351 (55\%) & $28859(50 \%)$ & $10471(49 \%)$ & $128681(53 \%)$ \\
\hline $\begin{array}{l}\text { Follow-up (yr), } \\
\text { median (IQR) }\end{array}$ & $16(11.1,16.0)$ & $16(13.8,16.0)$ & $15(13.2,16.0)$ & $16(13.8,16.0)$ & $16(15.1,15.9)$ & $16(13.9,16.0)$ & $13(11.6,14.2)$ & $16(13.0,16.0)$ & $9(8.9,9.6)$ & $11(9.8,10.5)$ & $13(9.5,16.0)$ \\
\hline $\begin{array}{l}\text { Screened at least } \\
\text { once, } n(\%)\end{array}$ & 3908 (91\%) & $23771(74 \%)$ & $5730(79 \%)$ & $16502(95 \%)$ & $1056(100 \%)$ & $4484(76 \%)$ & $4810(97 \%)$ & $60261(83 \%)$ & $8121(28 \%)$ & $4143(38 \%)$ & 72525 (64\%) \\
\hline $\begin{array}{l}\text { Screening tests } \\
\text { done }(n)\end{array}$ & 6446 & 52142 & 12731 & 40358 & 1846 & 15475 & 12068 & 141066 & 10060 & 5358 & 156484 \\
\hline $\begin{array}{l}\text { Screening rounds } \\
\text { per man (mean) }\end{array}$ & 1.5 & 1.6 & 1.8 & 2.3 & 1.7 & 2.6 & 2.4 & 1.9 & 0.3 & 0.5 & 1.4 \\
\hline Positive tests $(n)$ & 1058 & 5925 & 1443 & 9552 & 354 & 2896 & 2599 & 23827 & 1627 & 821 & 26275 \\
\hline $\begin{array}{l}\text { Men with positive } \\
\text { tests, } n(\%)\end{array}$ & $914(21 \%)$ & $4635(14 \%)$ & $1054(15 \%)$ & $6793(39 \%)$ & $326(31 \%)$ & $1537(26 \%)$ & $1729(35 \%)$ & $16988(23 \%)$ & $1560(5 \%)$ & $760(7 \%)$ & $19308(17 \%)$ \\
\hline Biopsies $(n)$ & 752 & 5404 & 902 & 8541 & 263 & 2509 & 2027 & 20398 & 468 & 418 & 21284 \\
\hline $\begin{array}{l}\text { Biopsies/positive } \\
\text { tests (\%) }\end{array}$ & 71.1 & 91.2 & 62.5 & 89.4 & 74.3 & 86.6 & 78.0 & 85.6 & 28.8 & 50.9 & 81.0 \\
\hline $\begin{array}{l}\text { Men with biopsy at } \\
\text { least once, } n(\%)\end{array}$ & $684(75 \%)$ & $4336(94 \%)$ & $741(70 \%)$ & $6187(91 \%)$ & $244(75 \%)$ & $1430(93 \%)$ & $1494(86 \%)$ & 15116 (89\%) & $468(30 \%)$ & $410(54 \%)$ & $15994(83 \%)$ \\
\hline \multicolumn{12}{|c|}{ Prostate cancer cases, screening group } \\
\hline $\begin{array}{l}\text { Prostate cancer } \\
\text { cases overall in } \\
\text { screening group, } \\
\text { total }(n)\end{array}$ & 482 & 3500 & 560 & 2376 & 92 & 814 & 620 & 8444 & 1718 & 747 & 10909 \\
\hline $\begin{array}{l}\text { Screen-detected } \\
\text { cancers }(n)\end{array}$ & 188 & 1632 & 197 & 1868 & 60 & 576 & 436 & 4957 & 229 & 128 & 5314 \\
\hline $\begin{array}{l}\text { Interval cancers } \\
\text { and cancers among } \\
\text { nonattendees }(n)\end{array}$ & 294 & 1868 & 363 & 508 & 32 & 238 & 184 & 3487 & 1489 & 619 & 5595 \\
\hline $\begin{array}{c}\text { Screen-detected } \\
\text { cancers/biopsy (\%) }\end{array}$ & 25.0 & 30.2 & 21.8 & 21.9 & 22.8 & 23.0 & 21.5 & 24.3 & 48.9 & 30.6 & 25.0 \\
\hline $\begin{array}{l}\text { Cumulative } \\
\text { incidence in } \\
\text { screening group } \\
(\%)^{\text {a }}\end{array}$ & 11.2 & 11.0 & 8.0 & 13.6 & 8.7 & 13.8 & 12.6 & 11.7 & 6.0 & 6.9 & 9.8 \\
\hline \multicolumn{12}{|c|}{ Prostate cancer cases, control group } \\
\hline $\begin{array}{l}\text { Prostate cancer } \\
\text { cases overall in } \\
\text { control cohort, } \\
\text { total }(n)\end{array}$ & 393 & 4546 & 452 & 1325 & 60 & 592 & 364 & 7732 & 1541 & 690 & 9963 \\
\hline $\begin{array}{l}\text { Cumulative } \\
\text { incidence in } \\
\text { control group (\%) }\end{array}$ & 9.2 & 9.4 & 6.5 & 7.6 & 5.3 & 9.9 & 7.4 & 8.7 & 5.4 & 6.6 & 7.8 \\
\hline
\end{tabular}


A

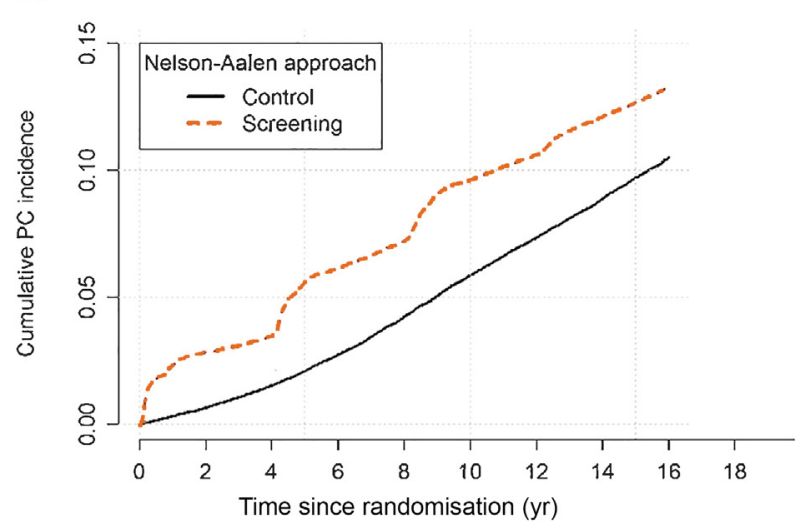

Number of men at risk

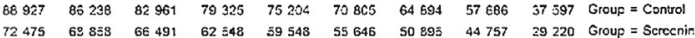

C

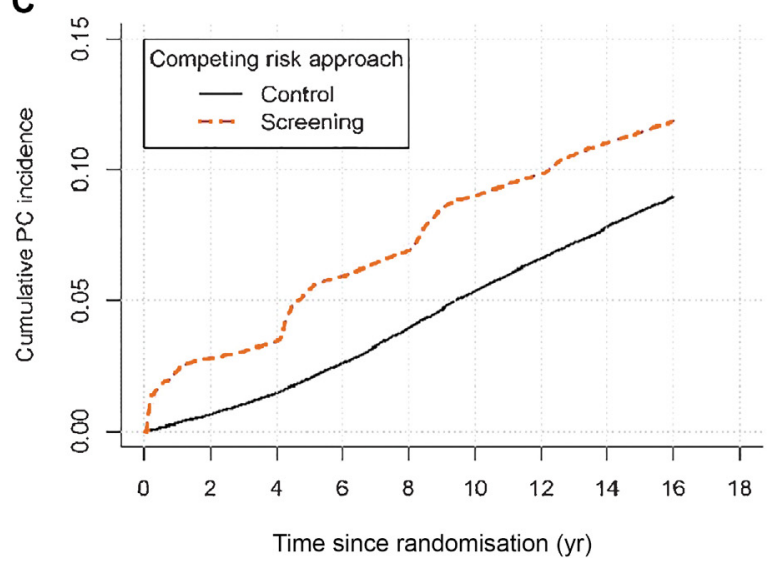

B

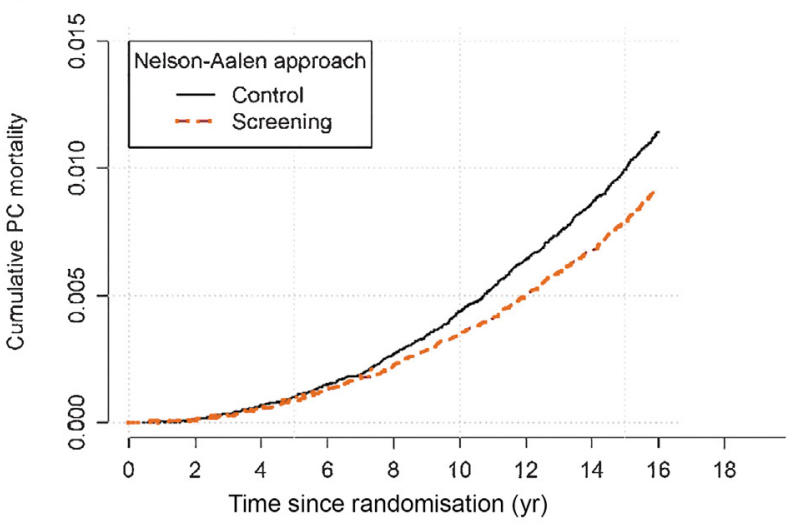

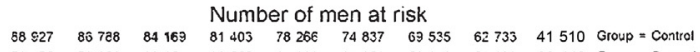

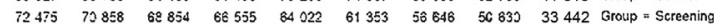

D

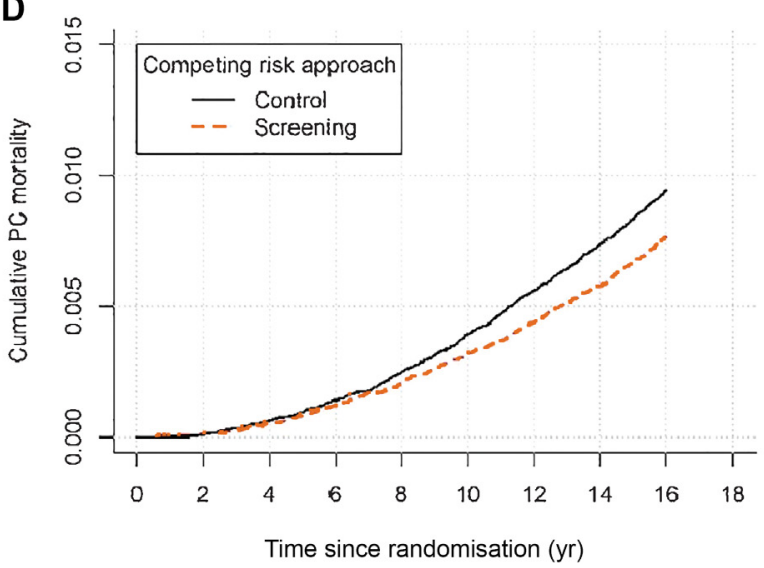

Fig. 2 - Prostate cancer incidence estimated by (A) the Nelson-Aalen approach and (C) the competing risk approach, and prostate cancer-specific mortality estimated by (B) the Nelson-Aalen approach and (D) the competing risk approach. $\mathrm{PC}=$ prostate cancer.

screening arm were screened on average 1.94 times (2.3 times in screening attendees), and of those participating, $28 \%$ were screen positive at least once (Table 1 ). Median follow-up (excluding France; from randomisation to a minimum of $16 \mathrm{yr}$, December 31, 2014, and the date of death) was $15.5 \mathrm{yr}$ and median follow-up from diagnosis to PCa cases was $8.8 \mathrm{yr}$ in the screening arm (10.3 in screen detected and 4.5 in clinically detected) compared with $5.4 \mathrm{yr}$ in the control arm. Cumulative PCa-specific incidence at $16 \mathrm{yr}$ was $13.3 \%$ in the screening arm and $10.3 \%$ in the control arm (Nelson-Aalen estimates) (Fig. 2). Hence, PCa incidence in the control arm compared with the screening arm increased during longer follow-up; however, the incidence still remained 1.4-fold higher in the screening arm after $16 \mathrm{yr}$ (Table 2).

The RR of PCa mortality between the arms was 0.80 at $16 \mathrm{yr}$ (95\% CI 0.72-0.89, $p<0.001)$ and did not change compared with 9,11 , and $13 \mathrm{yr}$ of follow-up (Table 3 ). The absolute difference between the trial arms increased from $0.14 \%$ at $13 \mathrm{yr}$ to $0.18 \%$ at $16 \mathrm{yr}$. The NNI was 570 and NND was 18 men (Table 3). PCa mortality by age at randomisation (5-yr age groups) is presented in Supplementary Table 1. Of the individual centres, a significant mortality reduction was seen in Sweden (RR 0.63, 95\% CI 0.44-0.88, $p=0.008$ ) and the
Netherlands (RR 0.67, 95\% CI 0.53-0.85, $p=0.001$; Supplementary Table 2). Supplementary Table 3 shows the distribution of PSA levels at diagnosis in the different screening rounds.

\subsection{Secondary analyses}

PCa-specific survival for cases detected during the first screening round was significantly worse compared with those diagnosed at subsequent screening rounds (hazard ratio $=1.86, p<0.001$; Fig. 3 ). The PCa mortality reduction in those who attended at least one screening round was $25 \%$ (RR 0.75, 95\% CI 0.66-0.75). The calculated PCa mortality reduction for those attending the screening programme at least twice was 48\% (RR 0.52, 95\% CI 0.42-0.63) if no mortality reduction was postulated from one test only, $43 \%$ (RR $0.57,95 \%$ CI $0.47-0.70$ ) if a mortality reduction of $10 \%$ was postulated, and 25\% (RR 0.75, 95\% CI 0.60-0.92) if first screening was as effective as the following rounds (Supplementary Table 4).

\section{Discussion}

This ERSPC update with 3 additional years of follow-up shows that the absolute reduction in PCa mortality still 
Table 2 - Prostate cancer incidence at various lengths of follow-up

\begin{tabular}{|c|c|c|c|c|}
\hline & Years 1-9 & Years $1-11$ & Years $1-13$ & Years $1-16$ \\
\hline \multicolumn{5}{|l|}{ Screening group } \\
\hline Prostate cancer $(n)$ & 6172 & 6852 & 7655 & 8444 \\
\hline Person years & 584776 & 695850 & 797774 & 918300 \\
\hline Rate per 1000 person years & 10.55 & 9.85 & 9.60 & 9.20 \\
\hline Risk per 1000 men & 85.16 & 94.54 & 105.62 & 116.51 \\
\hline \multicolumn{5}{|l|}{ Control group } \\
\hline Prostate cancer $(n)$ & 4154 & 5333 & 6384 & 7732 \\
\hline Person years & 735777 & 877302 & 1007337 & 1162062 \\
\hline Rate per 1000 person years & 5.65 & 6.08 & 6.34 & 6.65 \\
\hline Risk per 1000 men & 46.71 & 59.97 & 71.79 & 86.95 \\
\hline Rate ratio $(95 \% \mathrm{Cl})$ & $1.90(1.83-1.98)$ & $1.65(1.59-1.71)$ & $1.54(1.49-1.59)$ & $1.41(1.36-1.45)$ \\
\hline Rate difference per 1000 person years $(95 \% \mathrm{CI})$ & $5.00(4.69-5.31)$ & $3.86(3.58-4.14)$ & $3.35(3.09-3.61)$ & $2.66(2.42-2.90)$ \\
\hline Risk ratio $(95 \% \mathrm{CI})$ & $1.85(1.78-1.93)$ & $1.60(1.54-1.66)$ & $1.49(1.44-1.54)$ & $1.36(1.32-1.41)$ \\
\hline Risk difference per 1000 men $(95 \% \mathrm{CI})$ & $39.15(36.65-41.65)$ & $35.41(32.71-38.12)$ & $34.82(31.93-37.72)$ & $31.15(28.05-34.25)$ \\
\hline
\end{tabular}

Table 3 - Prostate cancer mortality at various lengths of follow-up

\begin{tabular}{|c|c|c|c|c|}
\hline & Years 1-9 & Years 1-11 & Years 1-13 & Years 1-16 \\
\hline \multicolumn{5}{|l|}{ Screening group } \\
\hline Prostate cancer deaths $(n)$ & 191 & 268 & 371 & 520 \\
\hline Person years & 612723 & 735205 & 848802 & 985382 \\
\hline Rate per 1000 person years & 0.31 & 0.36 & 0.44 & 0.53 \\
\hline Risk per 1000 men & 2.64 & 3.70 & 5.12 & 7.17 \\
\hline \multicolumn{5}{|l|}{ Control group } \\
\hline Prostate cancer deaths $(n)$ & 280 & 419 & 570 & 793 \\
\hline Person years & 749801 & 899370 & 1038723 & 1207411 \\
\hline Rate per 1000 person years & 0.37 & 0.47 & 0.55 & 0.66 \\
\hline Risk per 1000 men & 3.15 & 4.71 & 6.41 & 8.92 \\
\hline Rate ratio $(95 \% \mathrm{CI})$ & $0.84(0.70-1.00)$ & $0.78(0.67-0.91)$ & $0.79(0.69-0.90)$ & $0.80(0.72-0.89)$ \\
\hline$p$ value & 0.053 & 0.001 & $<0.001$ & $<0.001$ \\
\hline Rate difference per 1000 person years $(95 \% \mathrm{CI})$ & $-0.06(-0.12$ to 0.00$)$ & $-0.10(-0.17$ to -0.04$)$ & $-0.12(-0.18$ to -0.05$)$ & $-0.13(-0.20$ to -0.07$)$ \\
\hline Rate ratio, attenders & $0.78(0.63,0.96)$ & $0.72(0.60,0.86)$ & $0.73(0.63,0.85)$ & $0.75(0.66,0.85)$ \\
\hline$p$ value & 0.022 & $<0.001$ & $<0.001$ & $<0.001$ \\
\hline Risk ratio $(95 \% \mathrm{CI})$ & $0.84(0.70-1.00)$ & $0.78(0.67-0.91)$ & $0.79(0.70-0.90)$ & $0.80(0.72-0.90)$ \\
\hline Risk difference per 1000 men $(95 \% \mathrm{CI})$ & $-0.51(-1.04$ to 0.01$)$ & $-1.04(-1.67$ to -0.41$)$ & $-1.35(-2.09$ to -0.61$)$ & $-1.76(-2.63$ to -0.88$)$ \\
\hline $\mathrm{NNI}(95 \% \mathrm{CI})$ & 1947 (963-inf) & $962(598-2463)$ & $742(478-1650)$ & $570(380-1137)$ \\
\hline NND & 76 & 34 & 26 & 18 \\
\hline
\end{tabular}

increases with longer duration of follow-up, while the relative risk reduction remains unchanged at $20 \%$ since the initial report based on $8.8 \mathrm{yr}$ of follow-up [1-3]. PCa incidence in the control group is gradually catching up with the screening arm, but at $16 \mathrm{yr}$, a 41\% excess incidence remains in the screening arm. Results illustrate that both incidence and mortality differences continue to change between the two arms, and demonstrate why extended follow-up is required to better understand the long-term risks and benefits of PCa screening [13]. Despite a median follow-up of $15.5 \mathrm{yr}$ from randomisation, median follow-up from diagnosis (ie, $8.8 \mathrm{yr}$ in the screening arm and $5.4 \mathrm{yr}$ in the control arm) is quite modest given the natural course of PCa, as many screening-detected cancers are of low or intermediate risk with a long natural course [14]. Deaths among men with PCa diagnosed after screening termination will also affect the long-term impact of the screening trial, which will be observed in future follow-up.

The NNI to prevent one PCa death was 570 at $16 \mathrm{yr}$ compared with 1947 at $9 \mathrm{yr}$ and 742 at $13 \mathrm{yr}$ [1-3], an important decrease, emphasising the long-term impact of PCa screening. These figures differ from earlier publications, as in our first two, where no truncation was performed at 9 and $11 \mathrm{yr}$.

The number of cases needed to diagnose for averting one PCa death is declining from 48 in our first report at $9 \mathrm{yr}$ to 18 in this update at $16 \mathrm{yr}$. With extended follow-up, the NND will likely continue to decrease. Although it is difficult to compare screening programmes, at $16 \mathrm{yr}$, the NND in the Swedish centre was as low as 7 and comparable with that of breast cancer [15]. Nevertheless, the considerable NND reflects the abiding high excess incidence among screened 

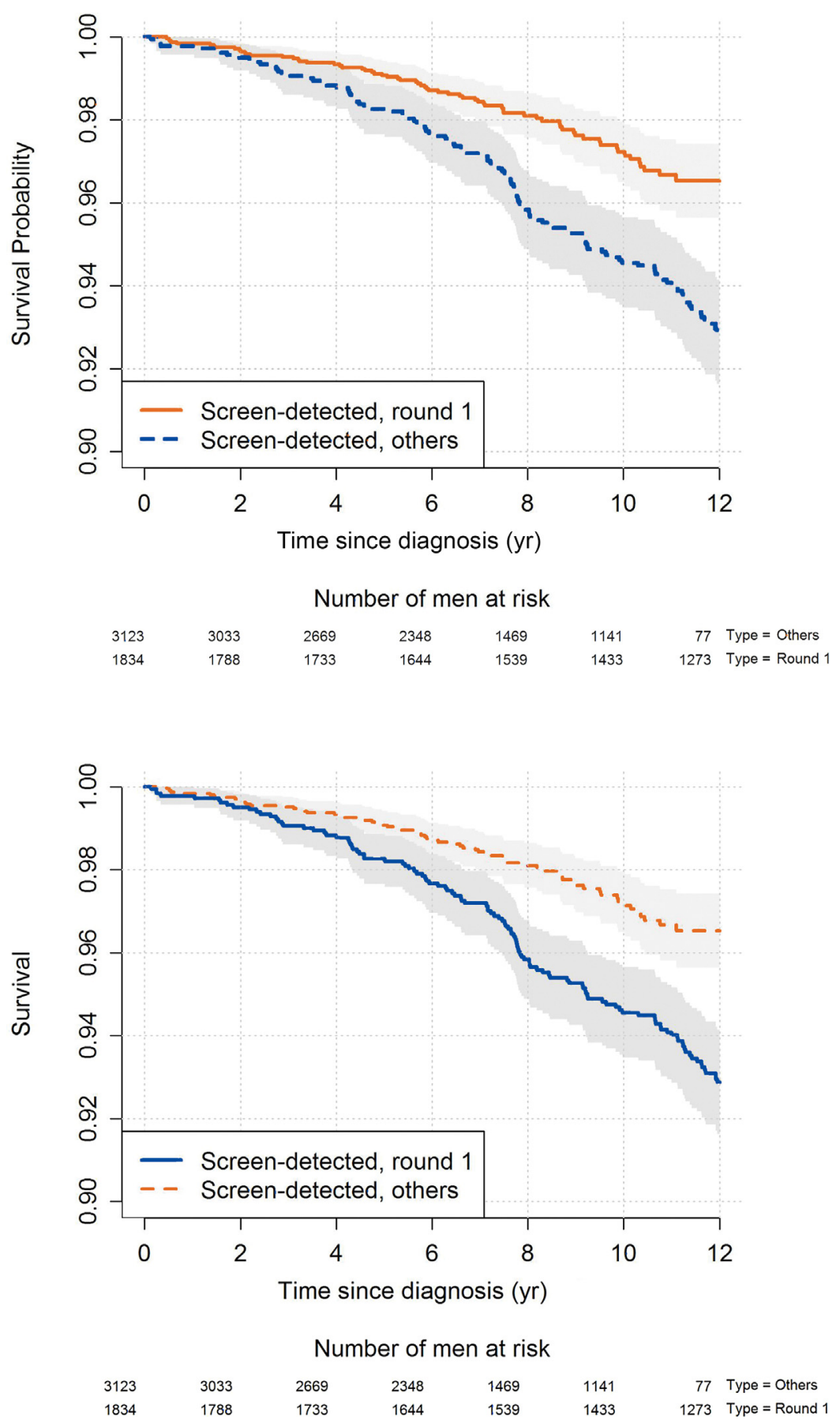

Fig. 3 - Prostate cancer-specific survival in those detected during round 1 screening and those detected during repeated screening.

men, indicating a substantial rate of overdiagnosis, even with many years of follow-up. The continued decline in NND many years after termination of PCa screening also reflects the long lead time of screen-detected PCa [16].

For screening decisions, this long symptom-free period has to be considered relative to early treatment with immediate side effects that might negatively affect the quality of life [17].

To detect roughly 5000 cancers, $>20000$ biopsies were performed, corresponding to a positive predictive value of
$24 \%$, and a quarter of participants were biopsied at least once, demonstrating the low specificity of PSA as a screening test. Development and use of more specific tests such as Prostate Health Index, $4 \mathrm{~K}$ score, and risk calculators must be prioritised, as well as improving the diagnostic work-up with less invasive diagnostic methods such as magnetic resonance imaging [18].

As in previous publications, we found a large difference in PCa mortality reduction between centres within ERSPC, with the largest effect observed in Sweden and the 
Netherlands [1-3]. In current analysis, these two centres show a relative reduction in PCa mortality by approximately $35 \%$. With different screening protocols and screening lengths between centres, outcomes were evaluated by the number of screening rounds. PCa mortality in men diagnosed in the first screening round had a significantly worse outcome compared with those detected at subsequent rounds (Fig. 3). One explanation is that many men diagnosed in the first screening round had incurable disease, whereas this was much less common in men detected at subsequent screening rounds. This is supported by the finding that the number of cancers detected with a PSA level of $>20 \mathrm{ng} / \mathrm{ml}$ was 182 (10\% of all PCa cases detected in that screening round) in round $1,72(4.1 \%)$ in round 2 , and only $42(3.2 \%$ ) in round 3 (Supplementary Table 3). As PCa with a PSA level of $>20 \mathrm{ng} / \mathrm{ml}$ to a high degree represents incurable $\mathrm{PCa}$, our data show that the majority of such cancers were in fact diagnosed during the first screening round. In this analysis, interval cancers were not added to the cancer cases designated to round 2 or 3 , which could be questioned. However, the rate of aggressive interval cancers is rare in PCa screening, and incorporation of these cases into the calculations will change the overall result only marginally [19].

These results suggest that a possible small beneficial effect of one-time screening may only "drown" in the high mortality rate of existing prevalent incurable PCa cases, while repeated screening over long duration is necessary for achieving a substantial and measurable PCa mortality reduction. Several lines of evidence support this view.

Cases detected within ERSPC during the first round frequently developed metastasis later, indicating that many of these men diagnosed during the first round were detected too late and screening could not prevent disease progression [20].

A screening trial (Stockholm, 1988-1989) invited 2400 men aged 55-70 yr only once and found no difference in PCa mortality after $20 \mathrm{yr}$ from a nonscreened source population; however, statistical power was limited [21]. Similar results were observed in the present study: men aged 70-74 yr were invited only once, and in this age group, no effect on PCa mortality was seen (Supplementary Table 1). No PCa mortality reduction was shown after $15 \mathrm{yr}$ in the US PLCO trial, which applied only $6 \mathrm{yr}$ of screening [22]. Despite several other components of this study may explain the PLCO null result, including large control group contamination, the short screening period may have contributed [23,24]. Within ERSPC, Finland showed only a small mortality reduction (RR 0.91 ) compared with the Netherlands (RR 0.67) and Sweden (RR 0.63). In Finland, the oldest age group where a quarter of the men were invited only twice, the mean number of screening visits was 1.6 . In the Netherlands, all men in the core age group were invited at least three times and the youngest up to five times, with on average 2.3 screening visits. In Sweden, all men were also invited at least three times and the youngest eight times, with on average 2.6 screening visits. The results from these three larger centres in ERSPC with different screening intensity indicate that the length and intensity of screening are directly correlated to mortality reduction (Table 1 ). The recently published CAP study invited 189386 clusterrandomised men to one-time screening, of whom $40 \%$ participated. They found no significant effect on PCa mortality (RR 0.96, CI 0.85-1.08; average follow-up $10 \mathrm{yr}$ ) [4]. The data encouraged us to analyse the effect of repeated screening rounds assuming various effects from one test only (Supplementary Table 4). Men attending at least one screening round had, after correction for nonattendance, a PCa mortality reduction of $25 \%$, and those who attended at least two screening rounds had a decrease of $48 \%$ assuming no effect of one-time screening. This model may explain the large differences in PCa mortality reduction observed between the centres within ERSPC, but other explanations may also contribute, for example, the rate of opportunistic screening in the control group (eg, Finland) [25]. This report shows that cancers detected in round 1 have a poorer prognosis, but this is partly due to the ERSPC study design where men started screening in various age cohorts with a median age of $60 \mathrm{yr}$ at randomisation. Older men screened for the first time showed a higher risk of being diagnosed with incurable disease [26]. In a running screening programme, men are invited from earlier age (50-55 yr), and the risk of missing the "window of cure" is probably lower. Furthermore, randomised screening trials will underestimate the true effect of an effective populationbased screening programme [27].

Our study has limitations including heterogeneous populations with different background risks between centres, possibly influencing the results. Another limitation is the increased uptake of opportunistic screening in Europe, which could underestimate the true effects of screening.

\section{Conclusions}

This 16-yr report from ERSPC shows that the absolute effect of screening on PCa mortality increases with longer followup. The excess PCa incidence among screened men is decreasing but is still rather high. The PCa mortality reduction seems to be related to the duration of screening, and a one-time screening test is suggested to have little or no effect on PCa mortality due to a prevalence pool of more advanced disease in which treatment is unlikely to provide major benefits.

\footnotetext{
Author contributions: Jonas Hugosson had full access to all the data in the study and takes responsibility for the integrity of the data and the accuracy of the data analysis.

Study concept and design: All authors.

Acquisition of data: Hugosson, Roobol, Tammela, Zappa, Nelen, Denis, Kwiatkowski, Lujan, Carlsson, Recker, Paez, Puliti, Villers, Rebillard, Bangma, Schröder, Auvinen.

Analysis and interpretation of data: Hugosson, Roobol, Månsson, Auvinen. Drafting of the manuscript: Hugosson, Kollberg.

Critical revision of the manuscript for important intellectual content: All authors.

Statistical analysis: Månsson, Moss.

Obtaining funding: Schröder.
} 
Administrative, technical, or material support: None.

Supervision: None.

Other: None.

Acknowledgements: Acknowledged persons are presented in Supplementary Table 5.

Financial disclosures: Jonas Hugosson certifies that all conflicts of interest, including specific financial interests and relationships and affiliations relevant to the subject matter or materials discussed in the manuscript (eg, employment/affiliation, grants or funding, consultancies, honoraria, stock ownership or options, expert testimony, royalties, or patents filed, received, or pending), are presented in Supplementary Table 6.

Funding/Support and role of the sponsor: ERSPC was supported by Hybritech Inc, but this sponsor had no access to data, no influence on data analysis or drafting of the manuscript. The maintenance of the Central database is sponsored by European Association of Urology.

\section{Appendix A. Supplementary data}

Supplementary data associated with this article can be found, in the online version, at https://doi.org/10.1016/j. eururo.2019.02.009.

\section{References}

[1] Schroder FH, Hugosson J, Roobol M, et al. Screening and prostatecancer mortality in a randomized European study. N Engl J Med 2009;360:1320-8.

[2] Schroder FH, Hugosson J, Roobol M, et al. Prostate-cancer mortality at 11 years of follow-up. N Engl J Med 2012;366:981-90.

[3] Schroder FH, Hugosson J, Roobol M, et al. Screening and prostate cancer mortality: results of the European Randomised Study of Screening for Prostate Cancer (ERSPC) at 13 years of follow-up. Lancet 2014;384:2027-35.

[4] Martin RM, Donovan JL, Turner EL, et al. Effect of a low-intensity PSA-based screening intervention on prostate cancer mortality: the CAP randomized clinical trial. JAMA 2018;319:883-95.

[5] ERSPC webpage. 2017 http://www.erspc.org/

[6] De Koning HJ, Liem M, Baan CA, et al. Prostate cancer mortality reduction by screening: power and time frame with complete enrollment in the European Randomised Screening for Prostate Cancer (ERSPC) trial. Int J Cancer 2002;98:268-73.

[7] De Koning HJ, Blom J, Merlebach JW, et al. Determining the cause of death in randomized screening trial(s) for prostate cancer. BJU Int 2003;92(Suppl. 2):71-8.

[8] Makinen T, Karhunen P, Aro J, et al. Assessment of causes of death in a prostate cancer screening trial. Int J Cancer 2008;122:413-7.

[9] Aalen O. Nonparametric inference for a family of counting processes. Ann Stat 1978;6:701-26.

[10] DeMets DL, Lan KK. Interim analysis: the alpha spending function approach. Stat Med 1994;13:1341-52, [discussion 1353-6].

[11] Kalbfleisch JD, Prentice RL. The statistical analysis of failure time data. New York, NY: Wiley; 1980.
[12] Cuzick J, Edwards R, Segnan N. Adjusting for non-compliance and contamination in randomized clinical trials. Stat Med 1997; 16:1017-29.

[13] Fenton JJ, Weyrich MS, Durbin S, et al. Prostate-specific antigenbased screening for prostate cancer: evidence report and systematic review for the US Preventive Services Task Force. JAMA 2018;319:1914-31.

[14] Rider JR, Sandin F, Andrén O, et al. Long-term outcomes among noncuratively treated men according to prostate cancer risk category in a nationwide, population-based study. Eur Urol 2013;63:88-96.

[15] Gotzsche PC, Nielsen M. Screening for breast cancer with mammography. Cochrane Database Syst Rev 2011;1:CD001877.

[16] Draisma G, Boer R, Otto SJ, et al. Lead times and overdetection due to prostate-specific antigen screening: estimates from the European Randomized Study of Screening for Prostate Cancer. J Natl Cancer Inst 2003;95:868-78.

[17] Heijnsdijk EA, Wever EM, Auvinen A, et al. Quality-of-life effects of prostate-specific antigen screening. N Engl J Med 2012;367:595-605.

[18] Kasivisvanathan V, Rannikko AS, Borghi M, et al. MRI-targeted or standard biopsy for prostate-cancer diagnosis. N Engl J Med 2018;378:1767-77.

[19] Roobol MJ, Grenabo A, Schroder FH, et al. Interval cancers in prostate cancer screening: comparing 2- and 4-year screening intervals in the European Randomized Study of Screening for Prostate Cancer, Gothenburg and Rotterdam. J Natl Cancer Inst 2007;99:1296-303.

[20] Schroder FH, Hugosson J, Carlsson S, et al. Screening for prostate cancer decreases the risk of developing metastatic disease: findings from the European Randomized Study of Screening for Prostate Cancer (ERSPC). Eur Urol 2012;62:745-52.

[21] Lundgren PO, Kjellman A, Norming U, et al. Long-term outcome of a single intervention population based prostate cancer screening study. J Urol 2018;200:82-8.

[22] Andriole GL, Crawford ED, Grubb RL, et al. Mortality results from a randomized prostate-cancer screening trial. $\mathrm{N}$ Engl J Med 2009;360:1310-9.

[23] Andriole GL, et al. Prostate cancer screening in the randomized Prostate, Lung Colorectal, and Ovarian Cancer Screening Trial: mortality results after 13 years of follow-up. J Natl Cancer Inst 2012;104:125-32.

[24] Tsodikov A, Gulate R, Etzioni R, et al. Reconciling the effects of screening on prostate cancer mortality in the ERSPC and PLCO trials. Ann Intern Med 2017;167:449-55.

[25] Kilpelainen TP, Pogodin-Hannolainen D, Kemppainen K, et al. Estimate of opportunistic prostate specific antigen testing in the Finnish Randomized Study of Screening for Prostate Cancer. J Urol 2017; 198:50-7.

[26] Hugosson J, Godtman RA, Carlsson SV, et al. Eighteen-year followup of the Goteborg Randomized Population-based Prostate Cancer Screening Trial: effect of sociodemographic variables on participation, prostate cancer incidence and mortality. Scand J Urol 2018;52:27-37.

[27] De Koning HJ, Gulati R, moss S, et al. The efficacy of prostate-specific antigen screening: Impact of key components in the ERSPC and PLCO trials. Cancer 2018;124:1197-206. 